\title{
Constellations of Ferry (Im)Mobility: Islandness as the Performance and Politics of Insulation and
}

\section{Isolation}

As geographers continue to study the significance of flows of people, material objects, and signs, mobility becomes "increasingly seen as a social good" whereas "immobility increasingly acquires, by contrast, the connotation of defeat, of failure, and of being left behind." ${ }^{1}$ But mobility (and relatedly accessibility ${ }^{2}$ ) is not inherently desirable. In spite of the burgeoning literature on mobility as a right ${ }^{3}$, as a condition for social equality, ${ }^{4}$ personal liberty ${ }^{5}$, as opportunity for a leisurely lifestyle ${ }^{6}$, and more broadly as a condition of cultural renewal ${ }^{7}$, mobilities can present distinct drawbacks which warrant serious academic scrutiny. Positing that mobilities can be undesirable does not imply the need to return to a sedentarist ${ }^{8}$ worldview, but rather is

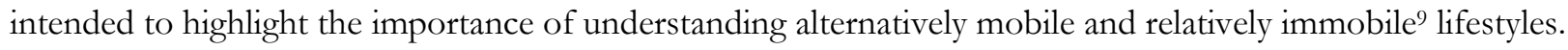

Barry's lifestyle exemplifies one type of these alternative mobilities. Driven "nuts," as he puts it, by the "rat race" and the "wheel-spinning" of metropolitan Vancouver, he up and left the city. He moved about 100kms up the British Columbia coast, to Texada Island. A mere 100kms in distance seems hardly a revolutionary break, but Barry had a clear plan in mind. "It takes three ferries to get here from Vancouver," he explains, “that's at least half a day's worth of travel. It's like I have three moats protecting me." Lisa, who was born and raised on Quadra Island, echoes Barry's feeling. "I grew up without fear," she says in a calm but confident tone, "my school friends and I could hitch-hike or play outside freely after school and there was never fear about what some stranger driving by might do to me." The practices, politics, and experiences of mobility of islanders like Barry and Lisa are the object of this paper.

Not unlike other kinds of rural and remote communities, islands hold great appeal for people wishing to live alternative lifestyles, people who often "retrofit" these communities to re-create utopian, idyllic spaces. ${ }^{10}$ By moving to and/or remaining in communities with a distinctly alternative ${ }^{11}$ disposition towards (im)mobilities and the preservation of the countryside 12 islanders opt for lifestyles which "protect"13 them from the ills of 
less desirable places. To understand the lifestyle of these islanders in this paper I employ the concept of “constellations of mobilities." 14 By it Cresswell refers to historically and geographically specific formations of mobility inclusive of relational experiences, practices, and politics. Different constellations have different characteristics. The constellations I examine here are marked by two characteristics in particular: insulation and isolation. These characteristics are the very hallmark of islandness. Stratford ${ }^{15}$ for example argues that isolation is experienced by Tasmanians as both a resource and a constraint because it affords distinction and uniqueness while at the same time constituting political and economic challenges. In this paper I differentiate between insulation and isolation and examine some of the ways in which they are practiced, felt, and struggled with in everyday life. Three components of mobility constellations in particular receive my attention: feel, route, and a third one not examined by Cresswell: remove. In doing so, I extend the mobility constellation concept. Simultaneously I shed empirical light on a much under-examined medium of mobility, the ferry boat.

The research reported here is part of a larger ethnographic project aimed at investigating the multiple roles played by ferry mobilities in the lives of British Columbia's ferry-dependent island and coastal community residents. With the exception of the largest island-Vancouver Island, which hosts a population in excess of 700,000 — almost all of these island and coastal communities are inhabited by 5000 residents or less. An extensive network of ferry boats owned and operated by BC Ferries provides access to all these communities. BC Ferries conducts operation in 47 ports of call situated on 22 islands and on the BC mainland through a multitude of routes ranging from 10 minutes to 36 hours in sailing length (see map 1). Because there are no fixed links in the region, these boats are lifelines. Some people may travel as frequently as almost every day or as infrequently as once, twice, or half a dozen times a year, or even once every twenty years. Regardless of personal travel frequency or purpose, conditions are very diverse across different ferry-dependent communities with regard to sailing frequency and duration, costs, and vessel size. Consequently different micro-constellations of mobility emerge. 
Map 1: The BC Ferries Network. Reprinted with permission. All rights reserved.

To capture the diversity of the various processes under study, mobile fieldwork ${ }^{16}$ entailed travel to, on, and from ferry boats, for a total of about 250 journeys over three years, and about 400 qualitative interviews conducted with a diverse sample of island and coastal residents. As an island dweller myself, I also have access to many experiences drawn from commuting. Parts of this paper, for example, were written in lineups and onboard boats on my way to the university office or elsewhere. Through my three ethnographic sections I display fragments and narrative data montages pastiched together from different bits of observation and conversation which display experiences, discourses, and practices of mobility. In order to capture some of the diverse components of mobility constellations, these montages portray different sites and circumstanceswithout aiming, however, to provide a representative picture of the diversity of experiences, practices, and politics.

\section{Conceptual Background and Geographic Context}

The concept of mobility constellation, argues Cresswell ${ }^{17}$, is a useful tool for describing the historical and political significance of multiple aspects of mobility. Sceptical toward the newness of the mobility paradigm and related claims ${ }^{18}$, and keen on showing instead the historical continuities of mobilities as a cultural phenomenon, Cresswell posits mobility constellations as "historically and geographically specific formations of movements, [and] narratives about mobility and mobile practices." ${ }^{19}$ Constellations of mobility simultaneously encompass practices, representations, socio-political dynamics and patterns of movement that only make sense as wholes, thus requiring a meso-theoretical relational approach. Such is the conceptual and analytical approach I build upon here.

Cresswell singles out six aspects of mobility as sensitizing concepts for research: motives, speed, rhythm, route, feel, and friction. These are constituent parts of "social relations that involve the production and 
distribution of power." 20 While all of these aspects are important to understand the empirical case at hand, given the limited space available here I only focus on two of the six aspects outlined by Cresswell: feel and route. As well, I introduce an aspect not examined by Cresswell: remove. Whereas feel refers to the affective experience of mobility, and route refers to the trajectory of movement, remove refers to the temporal and spatial performance of distance in which people engage in order to separate places from one another, or to bring them closer together. Route and remove can be related but are not synonymous. Whereas route refers to the channelling of motion along certain pathways, remove refers to the degree or stage of separation influencing motion between locations. The concept of remove is a universally important dimension of all spatial mobilities, but it is especially significant in those social contexts where it is strategically used, much like a material and technological resource,${ }^{21}$ in order to perform a consciously distinct lifestyle based on relative separation from a hegemonic counterpart.

A fruitful way to understand remove is to imagine it as a form of "spacing." 22 Like spacing, remove refers to "subjective and practical ways in which the individual handles his or her material surroundings"23_ distance in particular-by making sense of one's place in the world and by opening up or closing down possibilities for connection and disconnection through concrete forms of action. The concept of remove, like spacing writ large, is therefore intended to highlight what people do to separate or connect. The term "remove"-both as a noun and as a verb-denotes putting space in motion, or slowing down that motion. Utilization of this concept requires we frame place as a taskscape, a practical orientation, and embodied practice. As opposed to distance — which refers to the objective and measurable separation between two points—-the concept of remove implies openness and potential, actualized through performance.

Remove has played a key role in the project of modernity. ${ }^{24}$ Electronic and spatial mobility media ${ }^{25}$ are designed to increase connectivity and reduce the gaps separating people, bringing places closer together. To be removed, in fact, is often seen as being incommunicado and immobile and even to be "stuck" in the past. Within North America, for example, those who live in remote communities are derogatively known as 
"hillbillies": uneducated, incestuous, dangerous, retrograde simpletons unable to cope with the demands of life outside of rural areas. ${ }^{26}$ But being removed needs to be understood emically in its multiple dimensions and diverse contexts. Remove takes on especially dramatic significance on islands, as an island is a "sharply precise physical entity which accentuates clear and holistic notions of location and identity." 27 Because of the distinctiveness of their places, many islanders worldwide are in particular "suspicious, cynical or outright hostile to the effects—-socio-cultural, economic, environmental, and political—that being permanently connected to a metropolitan 'core' via a fixed link may have on their way of life." 28 While islands, smaller ones especially, obviously depend deeply on the externalities afforded by reliable access to the rest of the world, feelings of remove from that world seem to guarantee a more distinct collective and personal identity. The British Columbia archipelago presents us with interesting contemporary geographies of remove.

During the 1960s and 1970s many draft-dodging "back-to-the-landers"—or hippies_escaping the USA drifted northwest in search of communities believed to be safe from the tentacles of the American militaryindustrial complex. Their migration populated previously scarcely inhabited BC islands, deeply changing the values of these communities. Following their self-removal from their places of origin would soon come two additional waves. The first wave was comprised of urban retirees; a wave growing stronger with the ageing of the Baby Boom generation. For retirees being removed meant ensuring themselves a comfortable break from the busyness and/or drudgery of their past dwellings and lifestyles. Following and overlapping with the retiree wave was a progressive-minded creative and professional class who benefited from the arrival of high-speed internet and the forms of employment this technology made possible. Remove for them became a key to a more fulfilling lifestyle and the performance of a rural identity.

In sum, $\mathrm{BC}$ islands and remote coastal communities have historically afforded different people with the possibility of being removed from the rest of the continent, yet without being prohibitively far from it. This affordance has allowed them to cultivate lifestyles which have in common a marked ideological opposition to urbanism and suburbanism. In light of this it is no accident that most of these communities have very strong 
regulations and bylaws impeding the construction of fixed links, the development of land for even light industrial purposes, and land subdivision for high-density residential development— thus indexing a move toward a typically post-productive rural economy and society. ${ }^{29}$ Remove has thus been "incorporated" into a unique form of "dwelling" 30 and regional culture. Regardless of whether a person was island-born or not, being removed from the much maligned surrounding mainland plays a key role for identity performance. In what follows I examine in ethnographic detail the feels, routes, and remove of a small number of ferrydependent individuals and communities in order to shed light on some of the region's mobility constellations.

\section{Feel}

Someone should invent a small-island version of GPS technology, one that is not based on street names and civic numbers, but rather on the address system used by locals. Forget 1356 Sunrise Street or 123 South Road; the small-island GPS would just need to know whose house you live in and what funky stuff there is at the end of your driveway. Today I'm meeting Ken ${ }^{31}$, on Saturna Island. Ken hasn't lived at his house long enough for it to be known at "Ken's house." A guy by the name of John Barber lived there for twenty-four years before Ken moved in. So to all Saturna islanders Ken's house is known as John Barber's house. And "there is no civic number out front," he told me, "just keep driving when you get off the ferry. Once you see the large blue heron made of driftwood by the roadside, turn right at the next driveway." There map that, GPS!

Driving on small island roads is something special too. On my way to Ken's place today I have counted eight cars. The ferry was about to leave, so that explains the "heavy" traffic. I also counted two hitch-hikers. One of the hitch-hikers was picked up by a Toyota truck driving in front of me. The other was standing less than one-hundred yards before the driftwood heron, so close to my destination that I could not give him a ride. Feeling guilty given the local expectations to pick up hitch-hikers, I signalled to him with my fingers that I was only going a short way. "That's ok," he mumbled as I drove by. Accounting for actions to hitch-hikers is not the only hand-signal I've learned over the years of driving on small islands. Amongst my favourites are 
the salutations you are expected to exchange with drivers cruising past you on the opposite side of the road. You use the left hand index finger to acknowledge someone you don't know, the index and middle fingers to greet an acquaintance, all fingers except for the thumb (which is used to hold the steering wheel) for a friend, and the entire right hand in waving motion to salute a close friend (in which case the right hand is summoned to briefly hold the wheel).

As I step out of the car I meet Ken and his wife Desiree_-delightfully friendly people. They invited over to their house half the neighbourhood, about a dozen people. After the usual small talk and introductions we all sit around the living room and start talking.

"The one thing about Saturna that you need to know is the sense of community," the chorus begins.

"Neighbours know neighbours and they're the first people you call if you need anything."

“And your neighbours are also your source of entertainment. We don't go dining out here. When you feel like having a dinner with friends you pick up the phone and get a potluck going."

"Here people treat each other as people. We're all the same regardless of what we do. In this very living room there are retired academics, farmers, artists, ferry workers, nurses, and people who haven't held a job in twenty-five years..."

“Hey screw you Tom! I had a job in the late 90s!” interjects Frank. Laughter breaks out.

"Like I was saying," Tom picks up again, “we don’t worry about keeping up with the Joneses here, we accept each other's quirks, and respect the privacy of those who want to be left alone."

“And there's lots of quirks and freaks to put up with, let me tell you!” Gwen comments, provoking more laughter.

“That's true; people come here because of the sense of community and togetherness, but also because there is so much respect for strong, individual, unusual characters."

While the largest majority of island residents have come relatively recently to BC's islands from elsewhere, many who have been born and raised on islands choose to stay too, or perhaps to come back after a temporary move to the mainland for school or work. Whereas on many other islands of the world the 
division from "come-from-away" and "born islanders" is deep and the source of several conflicts, the reality here is different. In the words of a Saturna-born islander who told me about Ken and Desiree the day before I met them, "people like Ken and Desiree are true islanders. Not because they were born or raised here, but because they act like they belong."

"Someone here on Saturna yesterday," I tell the group, "told me that to be an islander you have to act like one. It doesn't quite matter whether you were born here or elsewhere. I'm curious about that. What does it mean to act like an islander? I mean, Is there, in your mind...” I ask, “an island personality of sorts?"

“Absolutely!" The chorus answers.

“Look, I'm a realtor, I can tell you within fifteen minutes of meeting a prospective client whether they're fit for island life or not, and I tell them straight up if it's not for them, because they'd be unhappy, and we'd be unhappy with them..."

“...yeah, you wanna watch out for people who bring their big city attitude here and don't change their expectations..."

“...the next thing you know they're putting up six foot fences, trying to start land development, or whining about the lack of this or that..."

"Yeah, yeah..." everyone agrees.

"But like I was saying," the realtor starts again, "people who come here have very, very strong characters. Whether rich or poor, they're self-sufficient, with an extreme send of independence, they're un-conventional, they're generally creative or crafty, they love peace and quiet and the outdoors, they're quirky, opinionated, and hate city life."

"Opinionated, yeah. I can vouch for that. A small islander's view of democracy is that he gets to be the one who decides everything!" More laughter breaks out.

"If you scratch the dirt off the skin of a small islander you find layers and layers of education and social consciousness. Not to say that everyone is progressive-minded, but even those who aren't formally educated like to read and have great respect for others' rights and dignity." 
“That's right, small islanders are die-hard individualists who like to be left alone, but they will give the shirt off their back to help out a neighbour or stand for a common cause."

“That's why you have so many grass-roots organizations, volunteer and interest groups."

“And let's not forget, that's also why you have factions and divisions. For every conservancy group you have a group with a large stake in land-development. Divisions are inevitable when you have a small community with very limited resources."

"And there are divisions over who is a true islander too. The full-time, year-round islanders often look down upon many of the seasonals and the weekenders for not being a true part of the community, for treating our island as a second bedroom, for not contributing to causes. There are times when the tension is strong." "Do you think that the ferry has anything to do with this?" I ask "I mean, would this island be the same with a bridge?"

"HELL NO!" everyone cries out.

"Everything would change with a bridge. We'd become a suburb."

"By limiting access to the rest of the world the ferry makes this place feel small, finite, different. It makes it what it is!"

"Yeah, the ferry makes an island feel like a coherent place, self-bound. It can bring unity, but because the escape is so limited it can work like a pressure cooker too, it can tear people apart.”

"Look, on a small island everything relates to the ferry, starting with who we are. We are drifters. Look around this room. Gwen is from the interior, Tom is from Vancouver, $\mathrm{Al}$ is from back east, Nadia is from Germany, and the list goes on. Ask around: we all came here because we wanted to break away.”

"The water separates you. The ferry cuts you off."

"Especially Saturna, you need two ferries to get here, this is the end of the line."

"We're not quite rural. These were hardly ever agricultural lands in the traditional sense. Fishing is more central to the island psyche than planting. Fish and fishing folk are mobile. None of us has their original roots here," Sigfried exclaims, "but we planted new roots here. At different times through the island's history there were different kinds of drifters. First it was the First Nations who'd come and go, then the pioneers, then the 
hippies, and now it's the retirees and the creative class and the environmentalists, but what we all have in common is that we wanted a very finite and remote community, we want to feel a strong sense of place and the ferry filters out those who are unfit for this community and funnels in those who crave it. And the ferry is there whenever we're ready to leave for a while, or to come back after we've left."

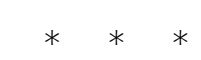

Experience lies at the core of mobility. 32 The way it feels to move has to do with how often, through what means and routes, and for what motives we move. Inspired by classical explorations of the experiences of mobility such as Wolfgang Schivelbusch's historical analysis of train travel ${ }^{33}$, a growing body of research has recently begun to shed light on the embodied experience of passengering. ${ }^{34}$ But even though research on passengering focuses exclusively on the phenomenological aspects of mobility as experienced whilst aboard means of transport, we do not cease to experience spatial mobility the moment we disembark. As Thrift writes "every space is in constant motion" 35 and thus the feel of mobility lingers on well past the act of riding. We are passengers at all times, constantly in betwixt and between old arrivals and new departures. The feel of mobility is thus pervasive, omnipresent. Lifestyles on small islands such as Saturna magnify the continuity of the feel of mobility practices.

While driving around small islands and remote coastal communities, walking on their roads or trails or beaches, and while navigating the landscape in search of particular locations, unique affective dimensions of mobility, different from those of the city, unfold. Of course it would be a mistake to view island spaces in clear opposition to urban spaces-because, as research shows, contemporary urban spaces have been to some extent ruralised while rural spaces have been urbanized and suburbanized. ${ }^{36}$ And to be sure, formal, faceless, distant, abstract, bureaucratic organizations of space are not entirely absent in small islands like Saturna Island, yet they are undeniably marginal in importance and they are often contested and dismissed by locals who much prefer idiosyncratic, informal, peculiar, localized, insider-only ways of relating to place. ${ }^{37} \mathrm{BC}$ islanders' identity and way of life, in this sense, are no different from many other islanders of the Western world. Bethel, for example, identifies informality and the importance face-to-face communication as one of 
the key traits of the Bahamian identity. ${ }^{38}$ And in his insightful remarks on the affective ties that bind islanders across the world's archipelagos, Putz, for example, identifies the following characteristics:

Independence — small boats and social circles demand it if a personality is to survive. Loyalty_ ultimate mutual care and generosity, even between ostensible enemies. A strong sense of honor, easily betrayed. Polydextrous and multifaceted competence, or what islanders call handiness. A belligerent sense of competition, interlaced with vigilant cooperation. Traditional frugality with bursts of spectacular exception. Earthy common sense. Opinionated machismo in both the male and female mode. Live-and-let-live tolerance of eccentricity. Fragile discretion within a welter of gossip. Highly individualized blends of spirituality and superstition. A complex oral tradition, with long memories fueled by a mix of responsible record keeping and nostalgia. And finally, a canny literacy and intelligence. ${ }^{39}$

Small islanders, similarly to other rural residents, ${ }^{40}$ find that small islands' sensescapes ${ }^{41}$ also feel remarkably different from cities'. "Islandness," writes Conkling, "means that you live a life closer to nature than most mainlanders do. The rhythms of tides, winds, and storms determine what you will do and what you will not do." ${ }^{42} \mathrm{BC}$ islanders routinely describe their sensescapes as quiet, placid, fraught with the smells, sounds, and sights of nature rather than human (read: industrial) presence. Given the extremely low population densities and limited development on the BC Coast, people's discourses about their sensescapes are not objectively unfounded. Human geographers have found similar qualities about other islands of course. For example, in describing the way a Prince Edward Island resident was taking in the landscape in a mundane, but deeply absorbing way, Weale writes that "when you live here for long, you take the island inside, deep inside. You become an Islander, which is to say a creature of the Island. Islandness becomes a part of your being, a part as deep as marrow, and as natural and unselfconscious as breathing." 43 
Together with a distinct sense of place and spatial organization, like many residents of rural places ${ }^{44}$ small islanders and coasters of $\mathrm{BC}$ also share a strong sense of community which is equally praised by locals as a mark of distinction. For Conkling the sense of community typical of islands is quite unique-marked, as it were, by the spatial boundedness and finiteness of an island. "What counts on islands, is that a community has to work together," he writes. He continues:

Island life is rigidly communal; the people you squabble with one day may save your life the next. When your car goes into a ditch, or your outboard quits halfway down to Mount Desert Rock, or you awake with chest pains in the middle of the night and need to get to the mainland fast, it's your neighbors who will bail you out. And you will do the same—not just out of neighborliness, but because a refusal to help threatens the safety of the entire community. Decision making on an island reflects this communal dimension. It's consensual, almost invisible. And the way consensus arises is through chatter: on the lobstermen's CBs, in the ferry line, at the post office waiting for the mail. 45

Both sense of place and sense of community are outcomes of the particular (im)mobility constellations typical of these ethnographic sites; ferries boats, local inhabitants invariably believe, filter out almost everything that is noxious about the outside world. All of these are ways in which ferries insulate. Insulation comprises feelings of protection, safety, distinction, and disconnection. Many BC islanders view the outside worldmost often pejoratively referred to as "the mainland"- as a runaway world of global hegemonizing trends, of constant directionless motion, of hurriedness and anonymity, of rude crowdedness and vacuous, fleeting relationships. Insularity is therefore "a source of pride," according to Yi-Fu Tuan. ${ }^{46}$ "No one wants to be treated like part of the woodwork," he argues, and the need to stand out above the crowd manifests itself in practices such as self-removal from the crowds of our large cities. Many of the islanders of the BC Coastespecially those living in smaller islands where "it's quite easy to be a big fish in a small pond," as an informant put it—want to be special, to be recognized for their "uniqueness." But this form of insulation from the most anonymizing tendencies of the urban crowd does not come without times "when even the 
most ardent individualists want to fade into the background, to sink into the reassurance and protective coloring of some larger being" 47 like the island community.

Of course these dispositions are not unique to islanders; rural residents of the world often feel similarly about city life and its alleged anonymity and rootlessness. ${ }^{48}$ But the small islands of $\mathrm{BC}$ present unique constellations of (im)mobility which point to the uselessness of juxtaposing nomadic with traditional, rooted, sedentary lifestyles. As Sigfried says in the ethnographic pastiche presented earlier most BC islanders and coasters are “drifters.” Drifters are not nomads. While nomads occasionally pause their travels whilst in search of new stomping grounds, drifters are explicit seekers of places in which to plant new temporary roots; their identities are moulded within continuous "place ballets" of departures and arrivals, rest and encounters 49. People who moved to islands after being born and raised elsewhere obviously epitomize this drifting persona, but many island-born residents also loosely identify themselves this way. Island youths for instance know they will sooner or later need to leave their small islands to seek higher education or work, though many of them know they will find a way to drift back in their adult years. Being an islander, in other words, is a constant process of becoming one by way of moving - whether moving to an island, moving back to an island, or simply removing oneself from the mainlands of the world by never leaving. ${ }^{50}$

As opposed to many other small and remote societies marked by parochial diffidence towards newcomers, including many of the world's small islands ${ }^{51}$, the remote coastal communities and small islands of Canada's West Coast are quite accepting of newcomers. Provided that newcomers "park their city-like attitude at the door," their meaningful integration into the community is almost immediate- though of course stronger time strengthens membership claims. This is in part because like gypsy traveller communities small islanders and coasters of $\mathrm{BC}$ have in common a desire "to know that they are part of something larger" and "to know where it is that they fit in" 52 as they move along their individualistic pathways. Amongst other means, ferries facilitate this integration process, by working as a common going concern (a feeling of "being all on the same boat," as it were), a mark of symbolic distinction and collective identity, and as an actual public square-like 
space where eventually, through repetition of travel ${ }^{53}$, everyone meets and runs into everyone else. In this sense islandness works performatively ${ }^{54}$ as something that can be expressed and "earned over time, by accepting the values and perspectives that that island life imposes," 55 as Putz observes "by adopting as one's own"56 as a type of life conversion.

Islanders view insulation as obviously a positive characteristic. But the very constellations of (im)mobilities which produce insulation also produce a much less desirable affect: isolation. Isolation is the other side of insulation; the reverse side of the process of de-synchronization from "the mainland." Isolation is an affective experience marked by vulnerability, marginality, and inescapability. Whereas islanders feel pride and joy about being insulated, they often feel angry and resentful about being isolated. One of the manifestations of isolation is found in how quickly conflicts can escalate, how long they can persist, and how pervasive they can become. Interestingly enough, the most evident sign of such isolation unfolds through the very feels of mobility. In the words of Betty, a Texada Islander, "the minute two or more people stop saying 'hi' to each other on the ferry or as they run into each other at the store you know something is wrong. For example, when I first moved here I didn't know we always waved at each other while driving. My neighbour called me on the phone to make sure I wasn't mad at her after I didn't wave at her as we crossed each other on the road. I had to reassure them everything was fine and that I just hadn't learned to behave yet!"

\section{Route}

All roads lead to Rome, an old Italian adage says. All ferry routes lead to the Richmond Comfort Inn, every islander and coaster knows. Almost all of the province's international flights and most of the cheaper domestic ones depart from YVR. Because very few morning ferry sailings leave early enough, it is vastly more convenient for a ferry-dependent community resident outbound on a morning flight from YVR to catch a night sailing, drive to the Comfort Inn, park the car at the free hotel parking lot instead of the expensive YVR lot, sleep, and catch the free airport shuttle, than it is to catch a seaplane or regular connecting flight to YVR. On any summer day the Richmond Comfort Inn feels like a Diaspora site. This morning the simple mention 
of the word "ferry" in a couple's louder-than-normal conversation started a round of "where are you from?" that revealed that four families, including mine, were here for the same reason. Katie and Sam and children were all born and raised and live in Powell River, Barry and Katia originate from the lower mainland but now live on Texada Island, and US-born Ruben and Galiano-born Jeanine reside on Galiano Island.

Barry was born and raised in the suburbs of Vancouver. For forty-one years he lived and breathed urban and suburban life, until one day in 1996 he and his wife and decided to go to Texada Island for a camping getaway.

“That ferry ride to Texada was like Avalon. It was like a homecoming. In the suburbs of Vancouver all you hear is sirens and tires screeching. Life is a rat race. On Texada I felt at home right away. That trip, with the three ferries it takes you to get there, is like a pilgrimage."

Land was relatively cheap then, so they bought a house on a whim. They would spend weekends there, holidays, and summers. All throughout this time Barry would find it harder and harder to drive back to the mainland, until he and Katia finally moved for good.

"This is the strange thing about Texada," he explains, "we are the largest island in the Strait of Georgia. When you go from Vancouver to Nanaimo the ferry could literally make a course correction on the way to Vancouver Island and drop off Texadans at the southernmost tip of the island. But instead, Texadans chose the northernmost side of the island to build a ferry terminal. So, instead of getting there from Vancouver in forty-five minutes we either take three ferries through the Sunshine Coast, or a ferry to Vancouver Island, one to Powell River, and one to Texada. Either route you take, it can take half a day or more."

While Powell River has several stores, services, and education and administrative centres, it is common for Texadans and Powell Riverites to catch the ferry to Comox, on central Vancouver Island.

"Every now and then you need to go over to the island, even just to get some new clothes. Otherwise we all start wearing the same clothes," says Katie with a grin.

“That's so true," laughs Katia, "and then we all run into each other at the malls on Vancouver Island!" 
"You know, in Galiano we have a bit of the opposite situation," says Jeanine, "we're exactly half way between Vancouver and Victoria. The Queen of Nanaimo gets you to Vancouver in about half an hour on her way east, but on her way west she stops all the gulf islands without getting to Victoria. Of course you can still go to Victoria with the Mayne Queen, but because you often have to transfer at Mayne Island it can be really more convenient for Vancouverites to come to Galiano, more than it is for Victorians."

As a result, Galiano Island has been feeling strong pressures for development. Whereas the route to Texada makes it inconvenient for an urbanite to spend a weekend at a cabin there, Galiano is a vastly more appealing choice for the part-timer and the vacationer coming from the city.

"And another interesting thing that you guys have going on with the Texada, Powell River, and Comox/Courtenay triangle is that you've very much part of each other's lives, aren't you?" asks Ruben. “That's right. Many families have members scattered around those three places," answers Katia. "Yes, whereas we in the Southern Gulf Islands are much less connected with one another. In the past the interisland ferry service was much stronger. People would do business on each other's island; the ferry was like a milk run between all the islands. Now the routes are such that it's only practical to go to Vancouver or Victoria."

"I guess what we do have in common, though, is that we all hate to go to the city, don't we?" laughs Ruben. "Don't get my husband started on that," smiles Katie, "every time we go to Vancouver he goes mental. "How can I not?" follows Sam, "Everyone is in a hurry. People are so short-tempered and stressed out. They all seem to be stuck in their work-mall-home mentality. No one says hi anymore. No one stays in the same place more than a couple of years. Everything is regulated, standardized, commodified, stricken by fear, by careerism, by greed. Every time I have to drive over the Lions Gate Bridge I start crying inside. All those cars. And it's such a long trip for us..." 
"Another thing we probably have in common is that none of us wants to become another Saltspring, eh?" says Barry.

Saltspring Island is the most populated and the most developed of the islands served by BC Ferries (except for Vancouver Island). Three ports and three ferry routes connect it to other places. Many islanders view Saltspring as an example of what the future can hold for them too unless they are vigilant against rampant development. The "Saltpsring index" — a semi-serious measure of development—gauges how developed an island is in comparison to Saltspring.

"Yeah you guys on Texada are probably around 35 years behind Saltspring," says Ruben, "we on Galiano need to watch out or we'll get there in a hurry. I'd much rather stay cash-poor and land-rich rather than sit on a two million dollar property and have to worry about my kids getting mugged by some drug dealer."

"Do you think that there is a danger with that attitude, though?" I ask "I'm obviously against unsustainable development but to make it easier for some people like young families to come to our islands by building affordable housing is important, and yet there are a lot of islanders who just have a drawbridge mentality." "Yeah, some people are like that," answers Barry. "They move to an island and then they think that nobody else should be let in after them. But you run into that mentality mostly when people talk about rich and insensitive Albertans or Americans who buy their second or their third home on an island. The drawbridge comes up against people like that, people who don't check their big city attitude at the door, who want come to an island to change it, to make it like the city they left."

"Yeah, you don't see much of that happening in places like Powell River or Texada," comments Katia, "the way to get there is too complicated for the average American and Albertan," she smiles, "three ferries, that slow, twisty road, you know, it's just too much for them. They're in a hurry. Barry's right, though. Everything would change if Texada was just a stop on the way from Vancouver to Vancouver Island. I need to find whoever put the ferry terminal at Blubber Bay and send them a card at Christmas!"

"Mobility is channelled," writes Cresswell, "it moves along routes and conduits often provided by conduits in space." 57 Routes shape constellations of (im)mobilities because through their "tunnelling effect" 58 they 
channel movement and thus designate possibilities for mobility and accessibility. Most BC's ferry-dependent communities are relatively close to one another, yet the routes ferries take in connecting them with one another and to urban areas are very diverse, making some destinations easily accessible and others extremely difficult to reach. For example, a trip to Texada Island from the greater Vancouver area requires a ferry passenger to ride three boats through the Sunshine Coast, whereas one simple and relatively short ride across the Strait of Georgia would suffice if the terminal was on the south side of the island. On the other hand, a trip from Vancouver to Galiano Island can take less than one hour and only one ferry ride. These routes have deep consequences for the shaping of small islands' cultures because they draw some communities into "intense interaction with each other" 59 while basically relegating others to the status of places on the margins. ${ }^{60}$

Routes are Janus-faced entities. On one hand, routes work as key technological affordances ${ }^{61}$ through which people shape the spatialities and temporalities of places. For example, in choosing to move to Texada Barry used-and continues to use — the complex route to Texada as a tool for insulation. Tired of the hustle and bustle of the city Barry wanted to move to a place where he could hide, and the route to Texada was for him a reflexive, strategic "technological choice." 62 Land developers interested in pursuing the potential of islands as weekend and seasonal gateways also view routes as key resources. Routes, it is evident, thus function as motility ${ }^{63}$ affordances which different actors choose to appropriate for different purposes, sometimes in harmony and at other times in conflict with one another.

Especially inconvenient and cumbersome routes aid islanders and coasters in their performance of a "radical rurality" which challenges the spaces of urban and suburban capitalism, consumerism, and the ideology of free mobility. In this sense, the more convoluted a ferry route is, the more radical one's performance of rurality can be. Radical rurality, according to Mormont, "is claimed not only as a space to be appropriated... but as a way of life, or a model of an alternative society inspiring a social project that challenges contemporary social and economic ill... Peasant autarky, village community and ancient technique are no longer relics, but 
images which legitimize this social project of a society which would be ruralized... The aim is not to recreate a past way of life but to develop forms of social and economic life different from those prevailing at present." 64

Complex routes, therefore, play a key role in the formation and maintenance of the island idyll. Like its better known counterpart, the idea of the rural idyll, ${ }^{65}$ the island idyll is comprised of a combination of affective elements such as natural bliss, an aura of authenticity investing social relationships and lifestyles, nostalgia for simpler times, unhurriedness, serenity, safety, heightened sense of control over one’s livelihood, and a pervasive romanticism infused into social arrangements and rapport with landscape. But in addition, the island idyll acquires typically insular characteristics that the absence of fixed links to mainlands seems to guarantee to most islands worldwide. Chief among the characteristics of this "lure of the island" is the clarity of identity that marine routes afford. Because the process of "getting there" is clearly distinct, the process of becoming an islander acquires qualities of uniqueness. As Peron remarks, it feels incredibly easy for islanders to say: "here, things are different" because "the omnipresence of the sea intensifies the feeling of being cut off from the rest of the world." ${ }_{60}$

However, on the other hand, routes are a key factor in fostering the marginalization of rural communities. ${ }^{67}$ When working at the expense of islanders and coasters, routes function as material transformations of mobilities, making and remaking the social geographies in which they operate. Because routes—both in terms of schedules and the direction of sailings-are determined by distant authorities (such as the BC Ferries Corporation) islanders and coasters often feel helpless about them. Thus, for instance, many Southern Gulf islanders have had to severely weaken or entirely cut off ties with residents of nearby islands because of poor inter-island scheduling or the absence of direct connections. This has had some notable deleterious consequences. Inter-island commerce, for example, has been seriously curtailed and thus these small islands have grown increasingly dependent on the larger urban areas of Vancouver Island and the mainland. Tourism development has also suffered in some destinations. For instance the route between Powell River and Comox 
has made it easy for tourists to travel between the two places, but the sailing schedule has made it infinitely more convenient for visitors to find overnight accommodations in Comox and then catch the ferry to Powell River in the morning rather than vice versa, thus seriously limiting the growth of the hospitality industry in the latter location.

"Spatial arrangements are reciprocally tied to movement processes" 68 and routes are the very channels shaping these processes and inviting or discouraging future movements, simultaneously insulating and isolating. Routes insulate from the outside world—the much maligned "mainland." But simultaneously routes isolate, making it necessary for islanders and coasters to take long, expensive, tiring trips to urban areas in search of services and goods funnelled out by the very limited accessibility of these small communities. The unintended consequences ${ }^{69}$ of routes are dramatic. Different routes and different uses of routes result in "contested choreographies"70 of marine highways, choreographies which over time pit people against one another: year-round islanders who wish to isolate themselves from the mainland versus seasonal residents who wish to make their island weekend destinations more convenient to reach; developers who wish to exploit the economic potential of land versus local conservationists who wish to protect and preserve; commuters who need to access a wider choice of jobs versus "hermits" who prefer independence and seclusion; young families who wish to give their children more access to educational and recreational opportunities versus wealthy retirees who view inconvenient routes and schedules as effective gates to their communities. Routes and their constellations of insulation and isolation are in sum deeply political and inevitably "implicated in the production and reproduction of power relations."

\section{Remove}

What does a Friday feel like for you? Like a fresh paycheck? Like a party? Like the start of a road trip? Could you get to that fine restaurant in New York City or that soccer match in Leeds in three hours' time, right before dinner time, or before the kickoff? What if you lived in Ocean Falls, BC? Where could you get...? 
“Shit man, I can't stand this, I don't even know why I came out, I'm going home. I hate Fridays. You need a ride back?"

"No thanks," I reply, "I can't miss this."

"Yeah this is the show you've been waiting for, isn't it?"

Indeed, this is it. This is ferry day. The Queen of Chilliwack only gets to Ocean Falls twice a week. She arrives at 2:00pm during the summer season. She comes from about 100 miles away as the crow flies. But you need to catch a ferry to get here. Ocean Falls is on the mainland but it is de facto an island: the mountains around it are too steep, the fjords protecting it too long, and the community too small to have many connection choices. The Chilliwack leaves for Ocean Falls from Port Hardy at 9:30pm on Saturday. She arrives on Monday at 12:45am. Then she slugs east to Bella Coola, from whence she loops back westward. She gets back to Ocean Falls at 2:00pm on Friday and eventually back south to Port Hardy, on the northeastern tip of Vancouver Island, at 9:00am on Saturday. So, there's your Friday. Could you get to Port Hardy's grocery store before the doors open? Could you run all your errands in that big town of 5000 residents in twelve hours, and then head back home? How would you like that for a weekend?

“This is just nuts, it's a freak show," Hank grumbles. The "freaks" are the tourists who bought a ride along the "Discovery Coast"—or as the locals might call it more mundanely, the $\mathrm{BC}$ central coast. The tourists are given two hours to explore the village of Ocean Falls while the crew is (sort of) busy unloading and loading. There are hardly ever more than forty or so tourists. "So, this is a ghost town, huh?"-I overhear an American tourist ask a local woman staffing a table at the weekly community "yard sale."

“Hum... not quite. I look haggard but I ain’t quite a ghost yet," she replies.

“How many times do people take you for a ghost?" I ask Hank, as I laugh.

"That's the part I hate the most," he answers, "people think that because there are abandoned buildings here nobody lives here. When they find out you do they think there's something wrong with you, that you're not quite human." Hank grew up here, so he has put up with enough of this in his lifetime. 
"I was talking to Emily earlier," I tell him, "and she was telling me how tourists would just open her house door and walk right in."

“That's right," Hank confirms, "with muddy shoes and everything. They'd walk straight into her living room and ask her what she was doing there."

"Doesn't it kill you to have to answer the same questions from them Friday after Friday?” I ask.

“That's why I don't come out here on Friday. See you later at the bar."

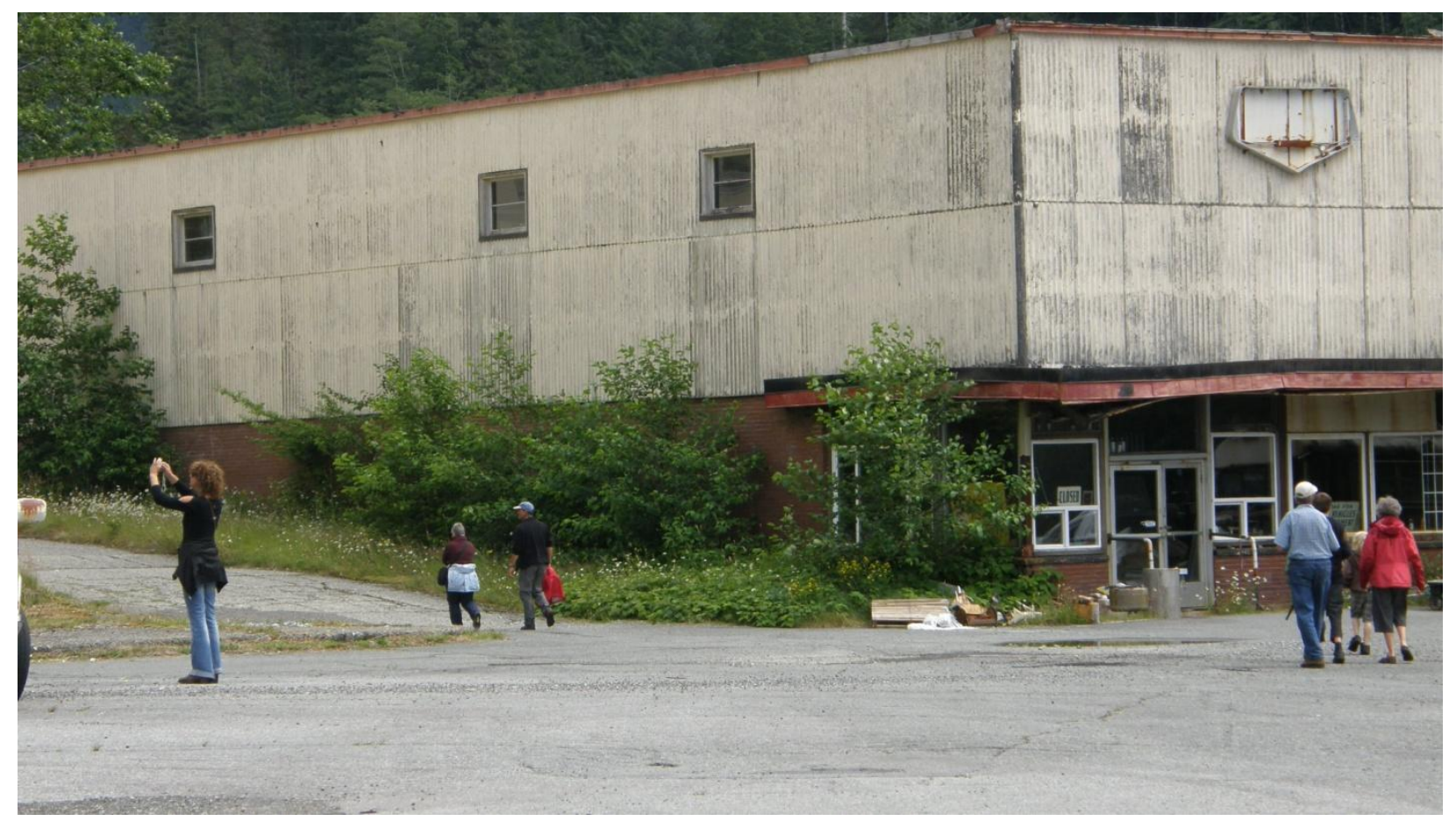

Picture 1: Ferry passengers venture out the streets of Ocean Falls in search of "ghostly" sites.

As Hank walks to his old truck the tourists disappear behind the old abandoned hotel. As far as nuisances go, the tourists' presence is quite minor, in my mind. It's a good way for the locals to pawn off old junk-some of which they found in abandoned buildings—as antiques and souvenirs to unwitting tourists. It's also a change of pace. There are less than 100 souls who live here, most of whom come here only during the summer. It's nice to see other faces and to have an easy target to make fun of, once a week. The tourists after all are but reminders that there is a world out there which deeply, undoubtedly, unmistakably "sucks"—a 
living reminder of why you decided to stay here or moved here in the first place and why, in the case of many, you haven't left for a few years.

I sort of like it here. I am in awe with the simplicity of this place. I wouldn't need to buy new clothes for the next twenty years if I lived here, and I'd still look spiffy. I would easily surrender the crap of everyday life: the whiny emails, (most of) the credit card charges, the stop lights, the loud fireworks on Canada day, and the crowded malls at Christmas time. This place reminds me of a very, very small island in many ways. The waters and mountains around it have formed a moat which keeps it safe from the toxicity of the rest of the world. Its rhythms are distinct, its sense of community strong, and its peacefulness and fresh air palpable in every breath you take. There are no sirens to be heard, no police or ambulances at all actually, no worries other than “will the mail get here today or it is too foggy for the seaplane to land?” Jeannie's words from an earlier interview capture well the sense of place

We're far. We're not on the way to anything. You don't stumble upon Ocean Falls. If you come to live here you make a lifestyle choice as dramatic as that of a man entering a convent. But don't get me wrong, this is no convent. Most people come here because they hate rules, bureaucracy, bullshit, busyness, the city, and all the nonsense they leave behind. And if they last here despite—or more like, thanks to - the lack of stuff to buy, shows to go see, and despite the fact that a round trip to the nearest supermarket takes three days at least, then they fall in love with this place and never leave again. Well, maybe except for a three hour drunken boat ride to Shearwater's pub.

But in all honesty, I couldn't last much longer than I have already. Like many young men my employment choices would be limited to three, maybe four different jobs. And I'm not "man" enough for any of them. My five year old daughter would be the only kid in school, if there was a school. My teenage stepson could only play fishing as a sport. My better half would go into convulsions due to withdrawal from high speed internet surfing. Even though this is no island, it's easy to catch island fever here. It's easy to miss family members living far away, it's easy to feel confined, besieged, and sheltered. And there's only that much time you can get 
by without a pub-made hamburger—as someone once told me. Those who catch island fever here know how easy it is to feel the toxicity of a place so small and so remote that a bad vibe can't help but continue to circulate in the veins of the community for years. "We recycle our clothes by passing them off to another, we share our food, we drink the same water, we walk on the same road," a woman by the name of Alice told me, "the moment one of our souls gets poisoned we all feel it; angry faces don't get lost in the crowd here." The other face of remoteness as shelter is remoteness as inescapability, as a vortex that spins you around slower and slower in no direction but the constant return to the same.

Various facets of mobilities "serve to differentiate people and things into hierarchies." 72 One of these facets is the degree or stage of remove that a community performs and experiences. As mentioned earlier, historically this form of remove has been crucial to the social, economic, and cultural development of coastal BC. To this day, such remove remains quintessential to the uniqueness of the BC coast's mobility constellations. Areas such as the central and north coast remain far from the nearest international airports, news media and advanced technology hubs, and both national and continental power centers. To some extent this remove is dependent on geo-physical distance, but to a larger extent remove is best understood with practices, representations, and power-based relations in mind. Not unlike other mobility technologies, the meanings of remove thus "depend on what kind of traveler you are" 73 and what kind of place you want to perform. ${ }^{74}$

Like an event ${ }^{75}$, degrees of remove unfold as mobile trajectories which intertwine or fail to intertwine, as they share or fail to share common directions. Like mobility as a whole remove is a "social activity of companions of people and things who move with, ${ }^{76 "}$ but also without, and against. Thus remove becomes meaningful in relation to how it is engaged with, how it is enacted, performed, and incorporated in everyday life. The ferrydependent communities of British Columbia vary greatly from one another in terms of remove. In communities like Bella Bella on Campbell Island, remove has allowed for the preservation of strong traditional aboriginal values, whereas in places like Ocean Falls remove, at different points in time, has been at the root of tourist flows as well as an out-migration that caused the near collapse of the community. These 
differences remind us of the changing roles played by remove in constellations of mobility both across place and time, and alert us to the need to understand how people remove themselves in desired ways.

The perception of place, according to Ingold, occurs through locomotion. Through our movements we alter not only our perception of the environment, but also the environment itself. Like a path carved after continuous walking, our footwork shapes the form of our landscape. Ingold's focus is exclusively on footwork, but other practices of mobility, such as riding ferries, do shape our environment. Small residents of islands and remote coastal communities transform the nature of the places in which they dwell by removing them from cities - by keeping cities far from islands, as it were, through the transport technologies they use. Thus, both islands and islanders "emerge as condensations or crystallizations of activity," 77 activities through which spatio-temporal distances are made significant, brought to life, woven into moat-like spaces.

An important difference between footwork and ferry mobilities exists, however. Footwork leaves footprints and forms paths and trails, but the riding of boats leaves no traces. Waterscapes bear no resemblances to fields. Whereas memories of movements become inscribed onto fields, they record no long-lasting material presence on lakes, rivers, and oceans. In this way waterscapes further remove travelers from whence they came. To be isolated is therefore to be truly removed, to be wiped clean of one's past—tabulae rasae ready "for any conceivable human project," writes Baldacchino. ${ }^{78}$ While islanders and coasters may be no ghosts, their social identity is indeed somewhat phantom-like-it is easy to remove oneself to a physical or de facto island in order to disappear. It is no accident that several residents of places like Ocean Falls have no phones, no IDs, and cars without license plates. Waterscapes easily afford this kind of removal from the rest of the world. This is certainly the case for someone like Hank; for him the ocean surrounding Ocean Falls is an arm keeping undesired others at length (at least almost every day of the week).

To live far, intensely removed from the mainland, is a key component of the expression of place identity on the BC Coast. The more remote one's island or coastal community, the more pronounced is the performance 
of one's distinction from urban life. If to be out of sight is to be out of mind on an island, ${ }^{79}$ then to be farther out of reach is to be farther out of sight and mind. In places like Ocean Falls—which are kept at the farthest reaches of the BC Ferry network — the differences between locals and visitors are highly dramatic. When the ferry arrives these differences are clearly staged. Whereas some locals hide out in their residences waiting for the "madness" to disappear, others come out to the ferry terminal simply to "look what the ferry dragged in today" and comment on interesting symbols differentiating locals from visitors. It is during times like these that the histrionic performance of remove becomes a matter of enforcing and reinforcing the symbolic meanings of being "out-of-place" and "in-place."

By encountering outsiders "dragged in by the ferry" locals perform remoteness ${ }^{81}$. By selling them junk as souvenirs and antiques the locals ridicule tourists' quest for the exotic. By witnessing their aimless walks about town the locals make a spectacle of the tourists. But by encountering locals upon exiting the ferry for a short exploratory walk of Ocean Falls tourists also perform their distinction. By taking pictures of the most mundane corners of Ocean Falls the tourists effectively objectify locals and their place as alien, grotesque Other(s), not unlike animals at a zoo. By calling Ocean Falls as a ghost town, visitors enact their identity as cosmopolitan and culturally dominant. As the ferry departs both locals and visitors then become insulated once again from one another; the locals go home to enjoy some rest and the newly found peace and privacy, and the visitors go back to the safety of their floating abode, often commenting on how "scary it was to think that there were wildlife predators lurking everywhere" and "how creepy it was to be in a god-forsaken town haunted by the ghosts of its past.” This way the performance of remove works both ways, as a relational process of mutual insularity.

Remove works as a relational process also with regard to isolation. Keeping separate from the rest of the region is very important in the consciousness of island and remote coastal community residents. Indeed reminders of the "tyranny of distance" 82 punctuate their everyday life. In Ocean Falls for example there is only one store where people may purchase convenience goods. The "Rain Country Store" sells frozen bread, 
frozen milk, and a small handful of other basic food at relatively high prices for periods of up to two and one half hours three days a week. Because catching the ferry just to go to the nearest supermarket is "basically insane," as a local put it, Ocean Falls residents send their large shopping orders to a shipping company operating out of the greater Vancouver area. Once every two weeks the barge—carrying a semi trailer half-full of goods-arrives to meet locals eagerly awaiting anything from cases of beer to toilet paper. As the barge docks the entire town comes to help unload it, occasionally throwing an improvised party with the freshly delivered goods. While the eccentricity and relative uniqueness of these rituals may seem like fun, the negative aspects of isolation are obvious when we think of the mundane complications distance originates. Remember the last time you had a piercing migraine, for example? How would you have felt if you had run out of aspirin and if you had had to wait one week to get medicated? Of course beside consumption isolation can seriously impact a community's economic sustainability as well. Ocean Falls has one of the Canada's largest untapped resources of hydroelectric power, but the way it has removed itself from the rest of the coast has severely limited its economic development. The "stranded mobility" 83 that such remove generates thus reinforces existing power geometries which further marginalize the rural and the remote. ${ }^{84}$

Furthermore, no drifter is ever quite happy to be stuck in the same place for too long without at least a short little escape. The "compulsion to proximity" 85 that the insulationist cultivation of remove denies cannot be completely annihilated. Occasional experiences of "island fever"—as nicely described by Alice—and stories of this frightening condition widely shared just like common myths are powerful enough to scare away prospective residents, push back most visitors, and occasionally pull away locals in search of a temporary way out of remove and isolation.

\section{Conclusion: Insulation and Isolation}

Throughout this paper I have argued that the affective dimensions, the routes, and the remove that characterize BC's ferry-dependent island and coastal communities shape unique constellations of (im)mobility. These constellations are characterized by a multitude of practices, representations, and politics 
that originate conditions of insulation and isolation. Insulation and isolation are two opposite sides of the same coin, as it were, the coin of islandness. Insulation refers to the more positive (as perceived by locals) dynamics occasioned by dwelling in communities that are one step removed from some of the hegemonic spatial mobilities practiced in large cities. Isolation refers instead to the more negative (again, as perceived by locals) dynamics which originate as a result of their peripherality and marginalization. Insulation and isolation are not only characteristics of these communities' constellations of (im)mobility but also the outcomes of the unfolding of these constellations. Indeed one might say that insulation and isolation are both meanings and consequences of these communities' (im)mobility constellations and of islandness.

My approach to (im)mobility constellations throughout this paper has emphasized the value of relationality. Understanding mobilities relationally means paying attention to how "mobilities involve how we form relations with others and indeed how we make sense of this." ${ }^{86}$ Islanders and coasters dwell in places where ferry mobility is constantly on the foreground of everyday life relationships-never too far from sensory awareness, from being a preoccupation, a subject of political dispute, or a topic for common talk. The very modern history of these ferry dependent communities is deeply entrenched in the history of marine mobility, and the biographies of islanders and coasters point to the important role that separation and disconnection from "the mainland" has played in their life decisions. In light of all of this, many of the people of the BC coast have learned to look at the ferries as more than just a means of transport. The ferries are for them a symbol of their relationship with one another, a mark of their distinction, and a tool that has carved alternative lifestyles and distinct places. Their common spatial mobilities, their shared and at times contested practices, politics, and power dynamics remind us how "mobility is never singular but always plural $[\ldots]$ never one but necessarily many" and how "in other words, mobility is really about being mobile-with." 87

It follows that islands' unique mobility constellations can only be understood in contrast to the mobility constellations of their urban and mainland counterparts. Through their alternative mobilities and lifestyles islanders and coasters abjectify the urban. The urban abject—an exaggeratedly negative rhetorical portrayal of 
city life_-solidifies island/urban oppositions on key characteristics of daily spatial mobilities such as fast (city) vs. slow (island), frantic and directionless (city) vs. calm and focused (island), and faceless and inhumane (city) vs. humane and personal (island). ${ }^{88}$ Islands are what they become in light of this performance of distinctiveness and boundedness, ${ }^{89}$ and it is light of this that we must understand how islanders view and practice their relative disconnection. But while remove from a mainland affords insulation, at the same time it never extinguishes the dialectic of openness and closure. The negative isolation that insulation fosters begs for some connectedness to be recuperated and maintained. ${ }^{00}$ As Baldacchino observes following Simmel "in separating two objects, we underline their connectedness" and "in connecting two objects, we simultaneously acknowledge and underscore what separates them." ${ }^{\prime 1}$ The idea of remove expresses well the relationality of this process: remove is a dynamic condition that begets both separation and connection, both insulation and isolation.

What I have also attempted to demonstrate through this paper is how constellations of (im)mobilities are multi-faceted, diverse, never subject to simple characterizations. The multiple sites of this fieldwork point to the many differences that characterize diverse experiences, routes, and distances—amongst other facets of (im)mobility constellations. The occasional struggles between different groups of residents-year-round vs. seasonal, commuters vs. tourists, etc.-point to the multiple dimensions of (im)mobility constellations and to the inadequacy of simplistic characterizations that would apply sedentarist metaphors to some and nomadic metaphors to others. In light of this, in my writing I have glossed over ascribed status categories such as newcomers and island-born residents and argued instead for the continued emergence of mobility constellations and therefore of isolation and insulation.

Mobilities have no inherent meanings for anything or anyone. Mobility and immobility practices, experiences, and politics can be marked by resistance and domination, contestation and liberation, and this case by insulation and isolation in nuanced ways that overlap, intersect, and even contradict one another, and in ways which are reflexive and strategic, and on the other hand in ways that are unpredictable and unplanned. Only a 
continued attention to the multiple constellations of (im)mobility of the world — thus not only to the same ones typical of "the city" — will shed light on their intriguing complexities. While it would be anachronistic to argue for an authentic islandness or even for "the idea of rurality as an isolated island of cultural specificity and traditionalism"92 given the interconnectedness of global and regional mobilities, it would be a mistake to be oblivious to the ways in which non-urban residents perform mobilities and relative immobilities in idiosyncratic ways in an attempt to cling on to, and thus produce, a place-specific way of life.

\section{Acknowledgement}

This research was made possible with by a Standard Research Grant from the Social Sciences and Humanities Research Council of Canada. I would also like to acknowledge the research assistance of April Vannini and the insightful comments of the editor and three anonymous reviewers.

\section{Biographical Note}

Phillip Vannini is Canada Research Chair in Innovative Learning and Public Ethnography, as well as Associate Professor in the School of Communication and Culture at Royal Roads University. His ethnographic research on ferry mobilities has appeared in such journals as Mobilities, Environment \& Planning D: Society and Space, Journal of Transport Geography, Time \& Society, Symbolic Interaction, Qualitative Inquiry, and the Canadian Joumal of Communication. He can be contacted at 2005 Sooke Road, Royal Roads University, Victoria BC V9B 5Y2, Canada. Email: phillip.vannini@,royalroads.ca

\section{Notes}

${ }^{1}$ D. Morley, Home Territories: Media, Mobility, and Identity (New York, Routledge, 2000), p. 202.

${ }^{2}$ Mobility and accessibility are not synonymous, but obviously related. On accessibility see J. Farrington, 'The new narrative of accessibility: its potential contribution to discourses in (transport) geography', Journal of Transport Geography 15 (2007), pp. 319-330.

${ }^{3}$ S. Bergmann and T. Sager (Eds), Ethics of Mobilities, Rethinking Place, Exclusion, Freedom and Environment (Surrey, Ashgate, 2008).

${ }^{4}$ T. Ohnmacht, H. Maksim, and M.M. Bergman (Eds), Mobilities and Inequality (Surrey, Ashgate, 2009); F. Rajè, Negotiating the Transport System (Aldershot, Ashgate, 2007).

${ }^{5}$ N.K. Blomley, Law, Space, and the Geographies of Power (New York, Guilford, 1994); M. Sheller, 'Mobility, freedom, and public space', in S. Bergmann and T. Sager, eds, The Ethics of Mobilities (Surrey, Ashgate, 2008), pp. 23-37.

${ }^{6}$ M. Kleinert, 'Solitude at sea or social sailing? The constitution and perception of the cruising community', in P. Vannini, ed., The Cultures of Alternative Mobilities: Routes Less Travelled (Surrey, Ashgate, 2009), pp. 159-176. 
${ }^{7}$ W. Canzler, V. Kaufmann, and S. Kesselring (Eds), Tracing Mobilities: Toward a Cosmopolitan Perspective (Aldershot, Ashgate, 2008); J. Urry, Mobilities (New York, Polity, 2007).

${ }^{8}$ T. Cresswell, On the Move: Mobility in the Western World (New York, Routledge, 2006).

${ }^{9}$ On the concept of relative immobility see P. Adey, 'If mobility is everything, then it is nothing: Towards a relational politics of (im)mobilities', Mobilities 1 (2006), pp. 75-94.

${ }^{10}$ On islands as everyday utopias see S. Royle, A Geography of Islands: Small Island Insularity (London, Routledge, 2007). On the retrofitting of rural communities by waves of amenity migration see J. Murdoch and T. Marsden, Reconstituting Rurality (London, UCL Press, 1994); P. Cloke, '(En)culturing political economy: A life in the day of a "rural geographer,"” in P. Cloke, M. Doel, D. Matless, M. Phillips, and N. Thrift, eds., Writing the Rural: Five Cultural Geographies (London, Chapman, 1994), pp. 149-190.

${ }^{11}$ P. Vannini (Ed.), The Cultures of Alternative Mobilities: Routes Less Travelled (Surrey, Ashgate, 2009).

${ }^{12}$ K. Halfacree, 'Rural space: Constructing a three-fold architecture, in P. Cloke, T. Marsden, and P. Mooney, eds., The Handbook of Rural Studies (London, SAGE, 2006), pp. 44-62.

${ }^{13}$ For a parallel conceptualization of the feeling of protection that islanders seek, see E. Stratfford, 'Isolation as disability and resource: Considering sub-national island status in the constitution of the "New Tasmania,' The Round Table 95 (2006), pp. 575-588.

${ }^{14}$ T. Cresswell, 'Towards a politics of mobility', Environment \& Planning D 28 (2010), pp. 17-31.

15 Stratford, 'Isolation as disability and resource.'

${ }^{16}$ L. Watts and J. Urry, 'Moving methods, travelling times', Environment \& Planning D 26 (2008), pp. 860874.

${ }^{17}$ Cresswell, 'Towards a politics of mobility.'

18 M. Sheller and J. Urry, 'The new mobilities paradigm', Environment \& Planning A 38 (2006), 207-226.

${ }^{19}$ Cresswell, 'Towards a politics of mobility,' p. 17.

${ }^{20}$ Cresswell, 'Towards a politics of mobility.' p. 21.

${ }^{21}$ On the use of technological resources by social actors see N. Oudshoorn and T. Pinch (Eds), How Users Matter: The Co-construction of Users and Technology (Boston, the MIT Press, 2005).

22 D. Crouch, 'Spacing, performing, and becoming: Tangles in the mundane,' Environment \& Planning A 35 (2003), 1945-1960.

${ }^{23}$ Crouch, 'Spacing, performing, and becoming', p. 1945.

${ }^{24}$ See for example N. Thrift, Spatial Formations (London, SAGE, 1996).

${ }^{25}$ J. Larsen, J. Urry, K. Axhausen, Mobilities, Networks, Geographies (Aldershot, Ashgate, 2006).

${ }_{26}$ T. Edensor, 'Performing rurality', in P. Cloke, T. Marsden, P. Mooney, eds, Handbook of Rural Studies (London, SAGE, 2006), pp. 484-492; K. Stewart, A Space on the Side of the Road: Cultural Poetics in an 'Other' America (Princeton, Princeton University Press, 1996).

${ }^{27}$ P. 272 in G. Baldacchino, 'The coming of age of island studies,' Tijdschrift voor Economische en Sociale Geografie, 95 (2004), pp. $272-283$.

${ }^{28}$ G. Baldacchino, 'Bridges and islands: A strained relationship,' in G. Baldacchino, ed., Bridging Islands: The Impact of Fixed Links (Charlottetown, PEI, Acorn Press, 2007), pp. 1-13.

${ }^{29}$ On post-productivist rural spaces see ee P. Cloke, 'The countryside: Development, conservation and an increasingly marketable commodity,' in P. Cloke, ed., Policy and Change in Thatcher's Britain (Oxford, Pergamon, 1992) pp. 269-95; Halfacree, 'Rural space: Constructing a three-fold architecture.'

30 On incorporation and the dwelling perspective see T. Ingold, The Perception of the Environment

(London, Routledge, 2000).

31 All names used here are fictitious.

32 Cresswell, On the Move.

33 W. Schivelbusch, The Railway Journey (Berkeley, University of California Press, 1987).

34 See for example Journal of Transport Geography, special issue on 'Geographies of the Passenger', forthcoming.

35 P. 141 in N. Thrift, 'Space', Theory, Culture \& Society 23 (2006), pp. 139-146.

36 See P. Cloke, "Conceptualizing rurality,' in P. Cloke, T. Marsden, and P. Mooney, eds., The Handbook of Rural Studies (London, SAGE, 2006), pp. 18-28. 
${ }^{37}$ In this sense the rhetoric of the evils of placelessness, typical of some humanist geography, is quite typical of coasters' and islanders' attitude toward urban life. For examples see E. Relph, Place and Placelessness (London, Pion, 1976); YF Tuan, Space and Place: The Perspective of Experience (London, Edward Arnold, 1974). Of course it is important to keep in mind, as Cloke observes in 'Conceptualizing rurality,' that the distinctions between urban and rural are themselves rhetorical achievements and that a responsible understanding of the differences between these spaces views them as continuums and not binary oppositions. ${ }^{38} \mathrm{~N}$. Bethel, 'Insularity versus cosmopolitanism in the Bahamas: Formality and informality in an archipelagic nation,' Social Identities 8 (2002), pp. 237-253.

${ }_{39}$ P. 16 in G. Putz, 'On islanders,' Island Journal 1(1984), pp. 26-29.

40 P. Cloke and C. Park, Rural Resource Management (London, Croom Helm, 1984).

${ }^{41}$ See P. Rodaway, Sensuous Geographies: Body, Sense and Place (London, Routledge, 1996).

${ }^{42}$ Conkling, 'On islanders and islandness,' p. 199.

${ }^{43}$ P. 81 in D. Weale, 'Islandness,' Island Journal 8 (1991), 81-82.

${ }^{44}$ See for example K. Halfacree, "The importance of "the rural" in the constitution of counterurbanization: Evidence from England in the 1980s,' Sociologia Ruralis 34 (1994), pp. 164-89; K. Halfacree, 'Talking about rurality: Social representations of the rural as expressed by residents of six English parishes,' Journal of Rural Studies 11 (1995), pp. 1-20;

45 P. 199 in P. Conkling, 'On islanders and islandness,' Geographical Review 97 (2007), pp. 191-201.

${ }^{46}$ Pp. 229-230 in Y-F. Tuan, 'Island selves: Human disconnectedness in a world of interdependence,'

Geographical Review 85 (1995), pp. 229-239.

47 Tuan, 'On islanders and islandness,' p. 230.

${ }^{48}$ D. Bell, 'Variations on the rural idyll,' in P. Cloke, T. Marsden, and P. Mooney, eds., The Handbook of Rural Studies (London, SAGE, 2006), pp. 149-159.

${ }^{49}$ D. Seamon, A Geography of the Lifeworld: Movement, Rest, and Encounter (London, Croom Helm, 1979).

${ }^{50}$ M.S. Gibbons, 'Islanders in community: Identity negotiation through sites of conflict and transcripts of power,' Island Studies Journal 5 (2010), 165-192.

51 See Conkling, 'On islanders and islandness;' J. Marshall and N. Foster, 'Between belonging: Habitus and the migration experience,' The Canadian Geographer 46 (2002), pp. 63-83.

${ }^{52}$ K. Hetherington, New Age Travellers: Vanloads of Uproarious Humanity (London, Cassell, 2000), p. 83.

53 Tuan, Space and Place.

54 Gibbons, 'Islanders in community.'

${ }_{55}$ Conkling, 'On islanders and islandness,' p. 198.

56 Putz, 'On islanders,' p. 26.

${ }^{57}$ Cresswell, 'Towards a politics of mobility', p. 24.

${ }^{58}$ S. Graham and S. Marvin, Splintering Urbanism: Networked Infrastructures, Technological Mobilities, and the Urban Condition (New York, Routledge, 2001).

${ }^{59}$ Graham and Marvin, Splintering Urbanism, p. 201

${ }^{60}$ R. Shields. Places on the Margin: Alternative Geographies of Modernity (London, Routledge, 1991).

${ }^{61} \mathrm{JJ}$ Gibson, The Ecological Approach to Visual Perception (London, Houghton Miffin, 1979).

${ }^{62}$ P. Lemonnier (Ed.), Technological Choices: Transformations in Material Culture Since the Neolithic (New York, Routledge, 2002).

${ }^{63}$ V. Kaufmann, Re-thinking Mobility: Contemporary Sociology (Aldershot, Ashgate, 2002).

${ }^{64}$ P. 18 in M. Mormont,'Rural nature and urban natures' Sociologia Ruralis 27 (1987),pp. 3-20; also see K. Halfacree, 'Rural space.'

${ }^{65}$ D. Bell, 'Variations on the rural idyll.'

${ }^{66} \mathrm{~F}$. Peron, 'The contemporary lure of the island,' Tijdschrift voor Economische en Sociale Geografie 95 (2004), pp. 326-339.

${ }^{67}$ For related arguments see PJ Cloke, M. Goodwin, and P. Milbourne, Rural Wales: Community and Marginalization (Cardiff, University of Wales Press, 1997). 
${ }^{68}$ P. 236 in R. Abler, J. Adams, and P. Gould, Spatial Organization: The Geographer's View of the World (Englewood Cliffs, Prentice Hall, 1971).

${ }^{69}$ E. Tenner, Why Things Bite Back: Technology and the Revenge of Unintended Consequences (New York, Vintage, 1997).

${ }^{70}$ T. Edensor, 'Snowboarders vs. skiers: Contested choreographies of the slopes', Leisure Studies 26 (2007), pp. 97-114.

${ }^{71}$ Cresswell, 'Towards a politics of mobility', p. 26.

${ }^{72}$ Cresswell, 'Towards a politics of mobility', p. 26.

${ }^{73}$ P. 19 in O. Lofgren, 'Border crossing: The nationalization of anxiety', Ethnologica Scandinavia 29 (1999), pp. 5-27.

${ }_{74}^{74}$ J Baerenholdt, M. Haldrup, J. Larsen, J. Urry, Performing Tourist Places (Aldershot, Ashgate, 2004).

${ }^{75}$ JD Dewsbury, 'Performativity and the Event: Enacting a Philosophy of Difference', Environment \& Planning D 18 (2000), pp. 473-496.

${ }^{76}$ P. Adey, Mobilities (London: Routledge, 2008), p. 23.

${ }_{77}$ T. Ingold, 'Culture on the ground: The world perceived through the feet', Journal of Material Culture 9 (2004), pp. 315-340.

${ }_{78}^{7}$ G. Baldacchino, 'Islands, island studies, island studies journal,' Island Studies Journal 1 (2006), pp. 3-18.

${ }^{79}$ G. Baldacchino, 'Islands, island studies, island studies journal.'

${ }^{80}$ T. Cresswell, In Place/Out of Place: Geography, Ideology, and Transgression (Minneapolis, University of Minnesota Press, 1996).

81 See Edensor, 'Performing Rurality'.

82 GK Zipf, Human Behavior and the Principle of Least Effort: An Introduction to Human Ecology (Cambridge MA, Addison-Wesley, 1949).

${ }^{83}$ M. Grieco and J. Hine, 'Stranded mobilities, human disasters: The interaction of mobility and social exclusion in crisis circumstances', in S. Bergmann and T. Sager, eds, The Ethics of Mobilities (Surrey, Ashgate, 2008), pp. 65-71.

${ }^{84}$ See D. Massey, Space, Place, and Gender (Minneapolis, University of Minnesota Press, 1994).

85 D. Boden and H. Molotch, 'The compulsion to proximity', in R. Friedland and D. Boden, eds, Now/ here: Space, Time and Modernity (Berkeley, University of California Press, 1994), pp. 257-286.

86 P. Adey, Mobilities, p. 19.

${ }^{87}$ P. Adey, Mobilities, p. 18.

${ }^{88}$ On the related topic of the rural abject see D. Bell, 'Variations on the rural idyll.'

89 P. Hay, 'The poetics of island space: Articulating particularity,' Local Environment 8 (2003), pp. 553-558.

${ }^{90}$ J.R. Gillis, Islands of the Mind: How the Human Imagination Created the Atlantic World (New York, Palgrave, 2004).

${ }^{91}$ Baldacchino, 'Bridges and islands,' p. 4.

92 P. Cloke, 'Conceptualizing rurality,' p. 19. 